\title{
Stand-alone single-frequency GPS ice velocity observations on Nordenskiöldbreen, Svalbard
}

\author{
M. A. G. den Ouden $^{1}$, C. H. Reijmer ${ }^{1}$, V. Pohjola ${ }^{2}$, R. S. W. van de Wal ${ }^{1}$, J. Oerlemans ${ }^{1}$, and W. Boot ${ }^{1}$ \\ ${ }^{1}$ Institute for Marine and Atmospheric research Utrecht, Utrecht University, Utrecht, The Netherlands \\ ${ }^{2}$ Department of Earth Sciences, Uppsala University, Uppsala, Sweden
}

Received: 24 June 2010 - Published in The Cryosphere Discuss.: 14 July 2010

Revised: 8 December 2010 - Accepted: 9 December 2010 - Published: 15 December 2010

\begin{abstract}
Precise measurements of ice-flow velocities are necessary for a proper understanding of the dynamics of glaciers and their response to climate change. We use standalone single-frequency GPS receivers for this purpose. They are designed to operate unattended for 1-3 years, allowing uninterrupted measurements for long periods with hourly temporal resolution. We present the system and illustrate its functioning using data from 9 GPS receivers deployed on Nordenskiöldbreen, Svalbard, for the period 2006-2009. The accuracy of the receivers is $1.62 \mathrm{~m}$ based on the standard deviation in the average location of a stationary reference station (NBRef). Both the location of NBRef and the observed flow velocities agree within one standard deviation with DGPS measurements. Periodicity $(6,8,12$, $24 \mathrm{~h}$ ) in the NBRef data is largely explained by the atmospheric, mainly ionospheric, influence on the GPS signal. A (weighed) running-average on the observed locations significantly reduces the standard deviation and removes high frequency periodicities, but also reduces the temporal resolution. Results show annual average velocities varying between 40 and $55 \mathrm{~m} \mathrm{yr}^{-1}$ at stations on the central flow-line. On weekly to monthly time-scales we observe a peak in the flow velocities (from 60 to $90 \mathrm{~m} \mathrm{yr}^{-1}$ ) at the beginning of July related to increased melt-rates. No significant lag is observed between the timing of the maximum speed between different stations. This is likely due to the limited temporal resolution after averaging in combination with the relatively small distance (max. $\pm 13 \mathrm{~km}$ ) between the stations.
\end{abstract}

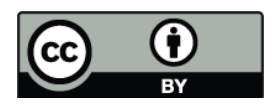

Correspondence to: C. H. Reijmer (c.h.tijm-reijmer@uu.nl)

\section{Introduction}

In the last few decades glaciers and ice sheets are losing ice mass at an increasing rate (IPCC, 2007; Oerlemans et al., 2007). For both glaciers and ice sheets ice dynamics play an important role in these volume changes. The dynamical response of glaciers to melt water production refers to increased production of melt water resulting in higher ice-flow velocities, and is a well known phenomenon (see e.g. Iken and Bindschadler, 1986). If the enhanced speeds last long enough, more ice is transported to lower elevations, resulting in increased melt. This positive-feedback mechanism could enable glaciers to react faster than expected to rising temperatures (Meier et al., 2007). Recent evidence suggests that this mechanism also yields higher ice-flow velocities in ice sheets, albeit temporarily (Zwally et al., 2002; Van de Wal et al., 2008; Shepherd et al., 2009).

IPCC (2007) acknowledged the importance of including ice-flow dynamics in sea-level forecasts and attempted to estimate its contribution. However, it also stated that the current state of understanding prevents a best estimate from being made. In more recent years several authors have addressed the effect melt water has on ice-flow dynamics and vise versa, and ultimately on sea-level forecasts (see e.g.; Bingham et al., 2008; Pfeffer et al., 2008; Van de Wal et al., 2008), but data are still sparse.

The IPY (International Polar Year) lead project the dynamic response of Arctic glaciers to global warming (GLACIODYN) was initiated to stimulate research to the aforementioned issue by coordinating model and observational studies on the dynamics and mass budget of Arctic glaciers. Within the framework of GLACIODYN, our research focusses on the relation between meltwater input and ice-flow velocities of Arctic glaciers. To assess this relation it is not only crucial to have detailed flow velocity information,

Published by Copernicus Publications on behalf of the European Geosciences Union. 
but also to have data on the mass budget, ice conditions (thickness and temperature), and surface and bedrock topography. In the past, ice-flow velocities were measured with stakes and traditional surveying methods, such as the use of theodolites. Nowadays, we have several airborne and spaceborne geodetic techniques at our disposal, such as the Global Positioning System (GPS) (Hinze and Seeber, 1988; King, 2004; Sunil et al., 2007), interferometric synthetic aperture radar (InSAR) (Joughin et al., 2008; Rignot et al., 2006), and speckle tracking techniques (Kääb et al., 2005). Although satellite remote sensing techniques provide valuable information on entire glaciers and ice sheets, the information is generally only available at time intervals of days to weeks. Therefore, GPS is indispensable in providing ground measurements, validation of the aforementioned techniques, and continuous measurements on a high temporal resolution.

Differential GPS techniques have been used for glaciological applications for several decades (Hinze and Seeber, 1988; Zwally et al., 2002). In May 2000, the Selective Availability, which caused an error of about $100 \mathrm{~m}$ in the location determined by stand-alone single-frequency GPS receivers, was switched off. This resulted in a substantially improvement in the accuracy of these systems (United States Air Force, 1996; USA Department of Defence, 2008). As a result, stand-alone single-frequency GPS receivers can now be used for glaciological applications such as ice flow velocity determination (Van de Wal et al., 2008). The Institute for Marine and Atmospheric research in Utrecht, the Netherlands (IMAU) has developed a low cost stand-alone single-frequency GPS unit, where stand-alone refers to no use of differential techniques, to perform year-round ice flow velocity observations. The purpose of this paper is to present this system, outline its possibilities and discuss its advantages and limitations. As an example, we present ice-velocity observations using this system on the glacier Nordenskiöldbreen, Svalbard, collected between 2006 and 2009, as part of the IPY-GLACIODYN project. In the remainder of the paper unless stated otherwise, GPS refers to a stand-alone single-frequency GPS receiver.

First, we describe the technical aspects of the system. Next, the measurements obtained at a stationary reference station are analyzed to illustrate the accuracy of the GPS unit. Subsequently, observations from 9 receivers located on the glacier Nordenskiöldbreen, Svalbard, provide information on the annual velocity of the ice, and its velocity variations on shorter time scales.

\section{Methods}

\subsection{GPS}

The GPS system consists of a constellation of 24 to 32 satellites. The satellites rotate in semi-synchronous $(11: 58 \mathrm{~h})$ orbits around the Earth repeating the same ground track once

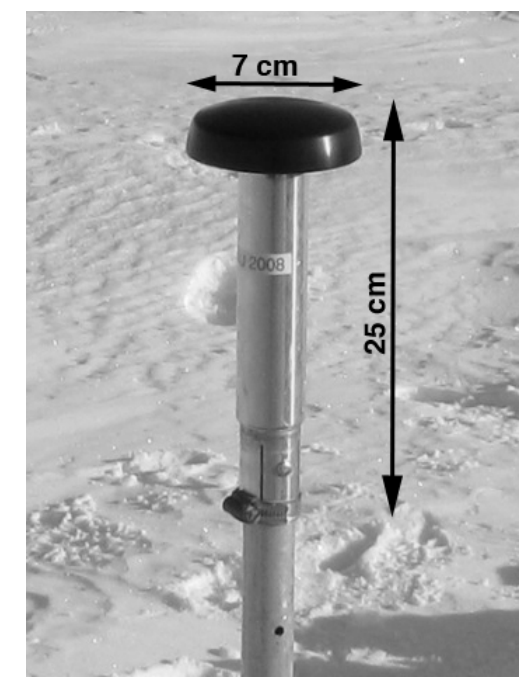

Fig. 1. GPS unit attached to a mass-balance stake.

every $23: 56 \mathrm{~h}$. The orbital planes in which the satellites orbit have an inclination angle of $55^{\circ}$ relative to the Earth's equator and a radius of about $26600 \mathrm{~km}$. Each GPS satellite continuously broadcasts information at two frequencies, the so called L1 and L2 bands. A GPS receiver calculates its position by precisely timing and analysing the signals sent by the GPS satellites (United States Air Force, 1996; USA Department of Defence, 2008).

The GPS setup (Fig. 1) evaluated in this paper determines its location based on a single-frequency signal (L1). The L1 signal carries so called Coarse/Acquisition (C/A) and Precise (P) encoded information containing satellite orbital information and clock information. Our GPS uses the C/A encoded information to determine the GPS location in the WGS84 reference frame. The achievable horizontal accuracy of a single observation using such a stand-alone single-frequency setup is between 13.6 and $22.7 \mathrm{~m}$ (HSAT value for a range of ionospheric delay estimates, USA Department of Defence, 2008).

The most important error sources in the determined positions are inaccuracies in the signal arrival time measurement, satellite orbital and clock information, atmospheric influences on the signal, multipath errors and satellite geometry (United States Air Force, 1996). The largest uncertainty is introduced by the influence of the atmosphere on the signal, especially the influence of the ionosphere. In the ionosphere solar radiation ionizes particles, changing the total electron content. This results in conductive layers which refract the GPS signal thereby increasing the traveling time of the signal.

Depending on the frequency bands and broadcasted information used and stored by the receiver, the accuracy of a GPS determined location can be improved (King et al., 2002). A number of methods and models can be applied to do so. These include making use of carrier phase information to 
determine the location, correct for the elevation of the receiver, correct the signal for tropospheric and ionospheric delay using both frequency bands (L1 and L2) or available models, and double differencing using two receivers and between satellite differencing to remove most of the above mentioned errors (King et al., 2002).

Our GPS uses about 15 Amp hour per year and when powered by one $3.6 \mathrm{~V}$ lithium battery can run for over 1 year without servicing. In order to limit the power consumption to these low values we only store time and positional data, and carry out as little computations as possible in situ. We therefore do not apply any of the above corrections and also cannot use differential techniques to minimize errors introduced by inaccuracies in the satellite orbital and clock information or ionospheric delay. Furthermore, our single frequency setup also prevents us from using the two bands to reduce ionospheric effects.

Our system determines and records its position at a preset time interval of 1 to $3 \mathrm{~h}$. From the consecutively stored locations, distances and thus velocities can be derived. For each stored observation, the GPS switches on for a period of 3 min until a stable signal is reached. This sampling strategy is based on the need to resolve diurnal variations and limiting power consumption. Every $24 \mathrm{~h}$ the system is initialised. For each subsequent observation within those $24 \mathrm{~h}$, deviations from the first observation are determined and stored. The only error source our system addresses is the multi-path error. This is done by making use of a patch antenna, which is an antenna that minimized the power received from below, in combination with the specific desing of our instrument (Fig. 1). The resulting accuracy of the observations is discussed in Sect. 4.

The GPS units can be placed on a tripod or mass balance stake. They are equipped with enough memory capacity and power supply to operate unattended for at least one year. In order to continuously monitor glacier velocities the GPS unit can be equipped with an Argos transmitter. First results obtained with this type of GPS instrument have been published by Van de Wal et al. (2008).

\subsection{Data processing}

To obtain ice-flow velocities from the locations measured by the GPS, the data is subjected to several processing phases. Firstly, we automatically remove the outliers. Then, when available, variations in observed position of a stationary reference station are subtracted from stations on the glacier. Note that this procedure is not comparable to e.g. differential techniques because no satellite information is used. However, it does remove some of the low frequency temporal variability. In the next step the stored positions are averaged. Subsequently, the distance between two positions is calculated and from that the velocities are determined. Finally, we average the velocities.
To remove outliers, the average $(\bar{\phi}(t), \bar{\lambda}(t))$ and standard deviation $\left(\sigma_{\phi}(t), \sigma_{\lambda}(t)\right)$ of the latitudinal $(\phi)$ and longitudinal $(\lambda)$ position are calculated over a period of $n_{\text {av }}$ hours. An entire record is excluded when the difference between two consecutive standard deviations $\left(\Delta \sigma_{\phi}(t, t+1), \Delta \sigma_{\lambda}(t, t+1)\right)$ exceeds a given threshold standard deviation for either the latitude or the longitude coordinate $\left(\Delta \sigma_{\phi}, \Delta \sigma_{\lambda}>\Delta \sigma_{\text {th }}\right.$, in $\mathrm{m})$. Note that $n_{\mathrm{av}}$ is only used to determine outliers, not for the velocity calculation itself.

To reduce the positional error, first the deviations from the average position of a reference station are determined and subtracted from the observations. Then running averages for the latitudinal and longitudinal coordinate are calculated over a preset period of $n_{\mathrm{p}}$ samples. The distance between two consecutive positions $(d \phi, d \lambda)$ and the direction of the displacement is then calculated taking into account the curvature of the Earth (Vincenty, 1975). Note that the curvature effect is small on $\mathrm{km}$ scale displacements. From the calculated distances the velocities $\left(v_{\phi}, v_{\lambda}\right)$ are calculated by dividing the distances by the time interval $(\Delta t)$. As a last step a running average is applied to the velocities using a period of $n_{\mathrm{V}}$ samples. Note that to prevent double use of data $n_{\mathrm{p}}$ is less or equal to $n_{\mathrm{v}}$. Note also that, $n_{\mathrm{p}}$ and $n_{\mathrm{v}}$ need not be the same as $n_{\mathrm{av}}$. The averaging period must be chosen such that the remaining standard deviation is smaller than the distance traveled in that period.

In the following $\sum_{i}$ is short for $\sum_{i=-n / 2}^{n / 2}$ and $i$ refers to number of timesteps:

$$
\begin{aligned}
& \overline{v_{\phi}}(t)=\frac{1}{\sum_{i} f_{i}} \sum_{i} f_{i} v_{\phi}(t+i) \\
& \overline{v_{\lambda}}(t)=\frac{1}{\sum_{i} f_{i}} \sum_{i} f_{i} v_{\lambda}(t+i) .
\end{aligned}
$$

These velocity components $\left(v_{\phi}, v_{\lambda}\right)$ are then combined to obtain the vector summed speed $\bar{v}(t)$. For calculation of the running averages it is possible to use different weighing functions $\left(f_{i}\right)$ for the used averaging window. Possible window functions are e.g. a square (boxcar), Bartlett, Welch, Hann or Gaussian window (Press et al., 2003). Except for the square window these window functions assign a heavier weight towards the centre of the window, which represents the observational time the average is assigned to.

A period average velocity can be determined in several ways. We present values determined by averaging all velocity values for a given period $\left(V_{\mathrm{av}}\right)$ and values determined by taking the distance between two (averaged) positions with the same time interval $\left(V_{\mathrm{be}}\right)$. The latter method has the advantage of being similar to the measurement strategy of more accurate differential GPS techniques where accurate position measurements are taken upon visiting a site. However, it has the risk of incorporating a relatively large error in one of the values depending on the chosen averaging period $\left(n_{\mathrm{p}}\right)$. 


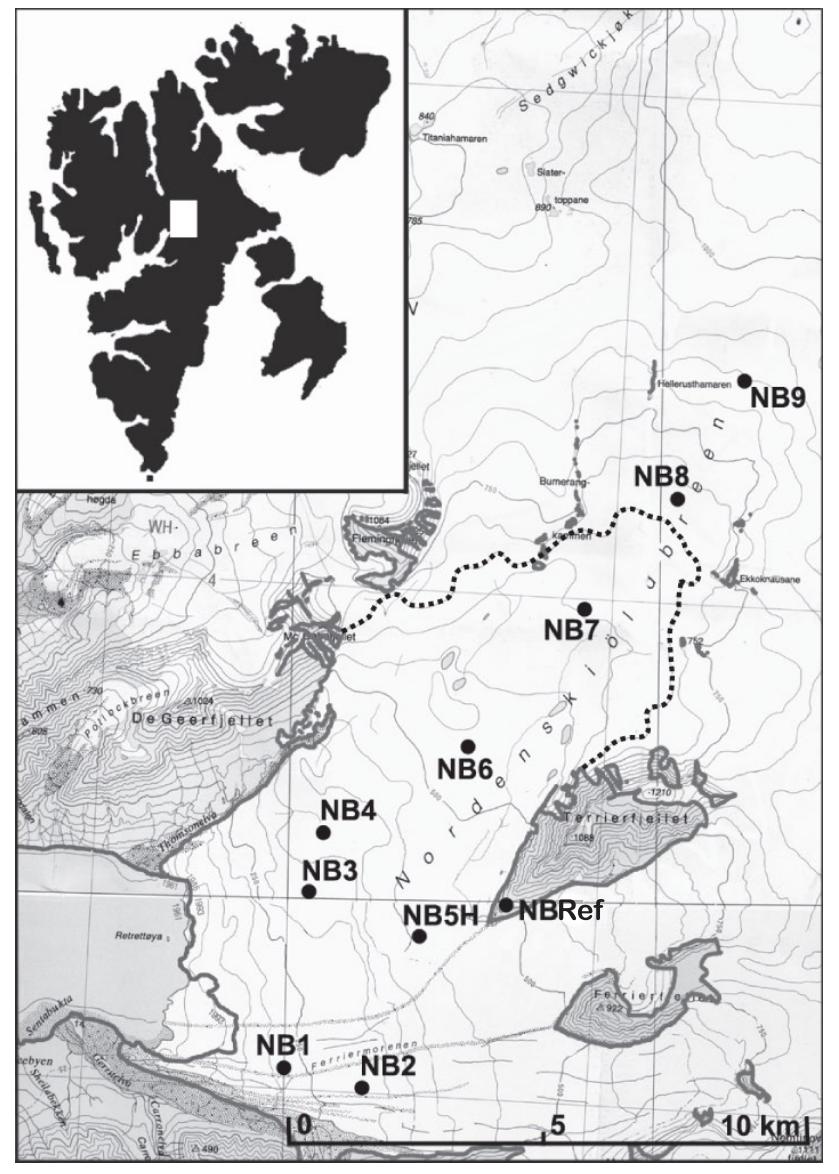

Fig. 2. Map of Nordenskiöldbreen (NP 1:100000, sheets C7, C8, D7, D8), Svalbard with the locations of the GPS stations (NB1NB9) and sonic ranger (NB5H) on the glacier, and the reference station on Terrierfjellet (NBRef). The approximate equilibrium line is indicated with a dashed line (Hagen et al., 2003).

\section{Data}

The data analyzed in this paper have been collected between March/April 2006 and May 2009 on Nordenskiöldbreen, Svalbard. Nordenskiöldbreen is a polythermal glacier located centrally on Spitsbergen $\left(78.6^{\circ} \mathrm{N}, 17.1^{\circ} \mathrm{E}\right)$, the main island of the Svalbard archipelago (Fig. 2). The glacier is an outlet glacier of the Lomonosovfonna ice plateau, which highest point is situated $1250 \mathrm{~m}$ a.s.l. While the glacier used to be a grounded tidewater glacier, recent retreat has caused it to currently partly terminate on land. The glacier is about $17 \mathrm{~km}$ long and $5 \mathrm{~km}$ wide (Hagen et al., 2003). The average thickness of the ice is approximately $300 \mathrm{~m}$, with a maximum of $600 \mathrm{~m}$ at the flat middle part of the glacier (R. Petterson, personal communication, 2010). Based on mass balance observations carried out during the same period, the average equilibrium line is at $605 \mathrm{~m}$, which is higher than the estimation of $550 \mathrm{~m}$ presented by (Hagen et al., 2003).
Table 1. Characteristics of the different GPS stations on Nordenskiöldbreen, Svalbard. Note that NB3 and NB9 were only active during the second year, while NB6 was lost in the second year.

\begin{tabular}{llrl}
\hline Station & $\begin{array}{l}\text { Altitude } \\
\text { [ma.s.1. }\end{array}$ & \multicolumn{1}{c}{ Period } & Description \\
& & \\
\hline NBRef & \pm 520 & 1 Apr 2006 to 28 Mar 2009 & Terrierfjellet \\
NB1 & \pm 135 & 1 Apr 2006 to 28 Mar 2009 & Side stream \\
NB2 & \pm 225 & 1 Apr 2006 to 28 Mar 2009 & Side stream \\
NB3 & \pm 335 & 28 Mar 2007 to 29 May 2009 & Main flow line \\
NB4 & \pm 345 & 31 Mar 2006 to 29 May 2009 & Main flow line \\
NB5H & \pm 435 & 30 Mar 2006 to 28 Mar 2009 & Sonic Ranger \\
NB6 & \pm 525 & 29 Mar 2006 to 17 Mar 2007 & \\
& & 4 Apr 2008 to 23 Mar 2009 & Main flow line \\
NB7 & \pm 590 & 1 Apr 2006 to 29 May 2009 & Main flow line \\
NB8 & \pm 675 & 1 Apr 2006 to 29 May 2009 & Main flow line \\
NB9 & \pm 875 & 27 Mar 2007 to 27 Mar 2009 & Main flow line \\
\hline
\end{tabular}

In total 10 GPS receivers provided hourly data during (a part of) the three year period (Table 1). Of these 10 stations, 9 are placed on ablation stakes on the glacier (NBX) and one on a tripod on rock serving as a reference site (NBRef). In order to study spatial variations in ice flow velocities the stations were placed in the ablation zone on, or close to the main flow line with \pm 100 altitude meters between the stations (NB3, NB4 and NB6-NB9, Fig. 2). NB3 was placed as close as possible to the calving front. Because the lower part of the glacier is heavily crevassed, NB5H is placed away from the main flow line and stations NB1 and NB2 are placed on a side stream. Additionally, at NB5H a sonic height ranger (Campbell SR50) is installed to measure the change in surface height, to determine the temporal variations in melt and accumulation. The specified accuracy of this system after temperature correction is $0.01 \mathrm{~m}$. NBRef is situated on the nunatak Terrierfellet (Fig. 2), and used to remove temporal variability not related to variations in glacier motion, and to asses the accuracy of the GPS system.

For comparison, the positions of the GPS stakes have been measured once a year with Trimble R7GNSS and DataGrid $\mathrm{mk} 3$ receivers. These systems use the differential carrier phase (L1, L2) method to accurately determine positions. The accuracy these systems can achieve after processing is respectively about $0.02 \mathrm{~m}$ and $0.1 \mathrm{~m}$ in the horizontal and vertical. Henceforth, DGPS refers to the above observations unless stated otherwise. Furthermore, the period average velocities $V_{\text {av }}$ and $V_{\text {be }}$ are compared with velocities determined by these measurements ( $\left.V_{\text {dgps }}\right)$, if available.

\section{Results}

\subsection{Reference station (NBRef)}

The fixed location of the reference station (NBRef) enables us to investigate the accuracy of our system in terms of the spread around the average observed location. It also provides 
Table 2. Description of the raw and processed data of the reference station NBRef. $n$ is the total number of records in 1 data set, $\sigma_{\mathrm{r}}$ is the combined standard deviation of the raw data, $\%$ is the percentage of correct data points, $\sigma$ is the combined standard deviation of the filtered non-averaged data, and $\sigma_{\phi}$ and $\sigma_{\lambda}$ are the standard deviations in the latitudinal $(\phi)$ and longitudinal $(\lambda)$ direction, respectively.

\begin{tabular}{crccccc}
\hline Year & $n$ & $\sigma_{\mathrm{r}}[\mathrm{m}]$ & $\%$ & $\sigma[\mathrm{m}]$ & $\sigma_{\phi}[\mathrm{m}]$ & $\sigma_{\lambda}[\mathrm{m}]$ \\
\hline $2006-2007$ & 8592 & 1.80 & 99.4 & 1.76 & 1.39 & 1.08 \\
$2007-2008$ & 9000 & 1.62 & 99.7 & 1.61 & 1.20 & 1.07 \\
$2008-2009$ & 8614 & 1.51 & 99.6 & 1.47 & 1.11 & 0.96 \\
$2006-2009$ & 26205 & 1.65 & 99.6 & 1.62 & 1.24 & 1.04 \\
\hline
\end{tabular}

an opportunity to investigate the effect of the automatic outlier removal and averaging procedures on the measured location and possible artifacts in our signal. Furthermore, measurements with the DGPS provide an additional valuable indication of the accuracy of the GPS measurements.

The purpose of removing the outliers is to reduce the standard deviation in the data set, without losing relevant information. Analysis of different combinations of the averaging period $n_{\mathrm{av}}$ and threshold standard deviation $\Delta \sigma_{\text {th }}$ shows that averaging over $60 \mathrm{~h}$ and a $\Delta \sigma_{\text {th }}$ of $0.1 \mathrm{~m}$ yields less than $1 \%$ data loss at NBRef, while the standard deviation is reduced to $\pm 0.5 \%$ of the annual average velocities encountered on Nordenskiöldbreen (Table 2). Note that for moving stations the best choice of $\Delta \sigma_{\text {th }}$ depends on the velocity of the glacier. Although the removal of outliers does not significantly change the annually averaged measured position of the reference station or the spread in the observations (Table 2), it is an important step for stations that show more outliers. In the remainder of the paper, the outliers are removed in the discussed data sets.

The standard deviation of the annually averaged position of NBRef is $1.24 \mathrm{~m}$ in the latitudinal direction, $1.04 \mathrm{~m}$ in the longitudinal direction, and $1.62 \mathrm{~m}$ combined (Table 2 ). The difference in standard deviation between the two orientations is due to the latitude of the observations, in combination with the orientation of the glacier and the slope of the nunatak on which NBRef is placed. Since the GPS satellites orbital planes make a $55^{\circ}$ angle relative to the Earth's equator, the maximum angle of the satellites above the horizon at $78.5^{\circ} \mathrm{N}$ is about $60^{\circ}$. As a result the location error caused by satellite geometry is larger in the latitudinal direction than the longitudinal direction. Shielding of the GPS is less important due to the gentle slope of the nunatak, the slope orientation of the nunatak and the other mountains surrounding the glacier.

As stated in Sect. 2.1, the largest uncertainty in the determined location is introduced by the signal delay in the ionosphere. This delay varies in time due to variations of the total electron content which varies diurnally, with the Suns 27-day rotational period, seasonally and according to the 11year Solar cycle. Signal delays between minimum and max-
Table 3. Comparison between GPS and DGPS measurements at NBRef. $\Delta \phi$ and $\Delta \lambda$ are the differences in the latitudinal and longitudinal direction, respectively, where negative values denote the positions to the south and/or west of NBRef. $\Delta$ total is the combined distance between the instruments, Dir is the direction from the GPS towards the DGPS location, and $H_{\mathrm{gps}}$ and $H_{\mathrm{dgps}}$ refer to elevation determined by the GPS and DGPS, respectively.

\begin{tabular}{lrr}
\hline & $25-03-2007$ & $03-04-2008$ \\
\hline$\Delta \phi[\mathrm{m}]$ & -1.04 & -0.15 \\
$\Delta \lambda[\mathrm{m}]$ & 0.52 & 0.58 \\
$\Delta$ total $[\mathrm{m}]$ & 1.16 & 0.60 \\
Dir $\left[^{\circ}\right]$ & 153 & 104 \\
$H_{\text {gps }}[\mathrm{m}]$ & $520.0 \pm 5.0$ & $518.3 \pm 2.6$ \\
$H_{\text {dgps }}[\mathrm{m}]$ & $547.9 \pm 0.015$ & $547.9 \pm 0.015$ \\
\hline
\end{tabular}

imum Solar ionospheric conditions can on average differ a factor of 3 to 4 with peak delays during high solar activity being 10 times greater for daily averages. Since the period of 2006-2009 is at a Solar ionospheric minimum the standard deviations are likely to be minimum values, and will probably increase in the coming years. However, the found standard deviation of $1.62 \mathrm{~m}$ is well below the the expected achievable horizontal accuracy of about $13.6 \mathrm{~m}$ for a single measurement using a stand-alone single-frequency receiver under low ionospheric delay conditions (USA Department of Defence, 2008). This can partly be explained by the $3 \mathrm{~min}$ in our system in which the signal can stabilize before the observation is stored.

The difference between the annually averaged position of NBRef and the DGPS is $1.16 \mathrm{~m}$ in 2007 and $0.60 \mathrm{~m}$ in 2008 (Table 3 and Fig. 3). The distances are within one standard deviation of the measured NBRef location. Part of the resulting difference can be explained by the fact that the DGPS was not placed on exactly the same location as NBRef requiring a correction. In both years, the offset is approximately in the same direction.

Based on the $1.62 \mathrm{~m}$ standard deviation in the NBRef observations in combination with our observational sample time of one hour and observed ice velocities of about $45 \mathrm{my}^{-1}$ (Tables 4 and 5) it is necessary to average the data to increase the signal to noise ratio in the observations. Figure 4 presents the combined standard deviation $\sigma$ in the NBRef observations when applying different averaging periods $n$ and window types. The figure shows that $\sigma$ is inversely proportional to $\sqrt{n}$, thus increasing the sampling frequency increases the resolved temporal resolution for constant $n$. An optimum is reach at a sampling interval of a few minutes, the time the system needs to receive a stable signal. After extensive testing we adopted a Welch window in our averaging procedure. Although the square window resulted in the fastest decrease of $\sigma$ with increasing window length $n$, it introduced spurious waves in the velocity time series. 




Fig. 3. Scatter plot of three years of non-averaged NBRef observations (black dots) with respect to the average location, negative values denote the records to the south and/or west of the average position. The grey dots indicate the location of the DGPS with respect to the averaged location, $1=2007,2=2008$. The circle denotes one standard deviation of the non-averaged NBRef data.

Table 4. Comparison between GPS and DGPS determined velocities of Nordenskiöldbreen. $V_{\mathrm{av}}$ is calculated using Eq. (1), with $n_{\mathrm{p}}=n_{\mathrm{V}}=240 . V_{\mathrm{be}}$ is based on the distance between the $240 \mathrm{~h}$ averaged beginning and end points of a GPS and $V_{\text {dgps }}$ is based on the yearly DGPS measurements. GPS values are calculated over the same period as spanned by the individual DGPS observations, which is about one year. Uncertainties in the GPS determined velocities are based on the standard deviations in the $240 \mathrm{~h}$ average locations.

\begin{tabular}{lcccc}
\hline Station & Period & $V_{\mathrm{av}}\left[\mathrm{m} \mathrm{yr}^{-1}\right]$ & $V_{\mathrm{be}}\left[\mathrm{m} \mathrm{yr}^{-1}\right]$ & $V_{\mathrm{dgps}}\left[\mathrm{m} \mathrm{yr}^{-1}\right]$ \\
\hline NB1 & $2008-2009$ & $2.7 \pm 0.4$ & $3.0 \pm 2.2$ & $3.1 \pm 0.02$ \\
NB2 & $2008-2009$ & $1.3 \pm 0.4$ & $5.1 \pm 2.2$ & $1.4 \pm 0.02$ \\
NB4 & $2006-2007$ & $47.6 \pm 1.1$ & $47.6 \pm 2.0$ & $47.6 \pm 0.02$ \\
& $2007-2008$ & $48.4 \pm 0.6$ & $48.2 \pm 1.8$ & $50.0 \pm 0.02$ \\
NB5H & $2007-2008$ & $24.5 \pm 1.1$ & $23.3 \pm 1.0$ & $24.9 \pm 0.02$ \\
NB6 & $2006-2007$ & $42.8 \pm 1.6$ & $42.8 \pm 2.7$ & $42.1 \pm 0.02$ \\
NB7 & $2006-2007$ & $46.2 \pm 0.7$ & $46.2 \pm 1.3$ & $51.6 \pm 0.02$ \\
& $2007-2008$ & $47.1 \pm 0.3$ & $47.1 \pm 1.1$ & $50.9 \pm 0.02$ \\
NB8 & $2006-2007$ & $40.6 \pm 0.4$ & $40.6 \pm 1.1$ & $38.4 \pm 0.02$ \\
& $2007-2008$ & $41.7 \pm 0.3$ & $41.5 \pm 1.0$ & $43.0 \pm 0.02$ \\
NB9 & $2007-2008$ & $55.9 \pm 1.4$ & $55.9 \pm 2.6$ & $54.5 \pm 0.02$ \\
& $2008-2009$ & $58.0 \pm 0.7$ & $57.7 \pm 2.4$ & $57.9 \pm 0.02$ \\
\hline
\end{tabular}

Therefore, a non-square function is preferred, of which the Welch window showed the fastest decrease in $\sigma$ with increasing $n$.

When applying a window length of $n=240$ (equivalent to $240 \mathrm{~h}$ ), $\sigma$ reduces to about $0.2 \mathrm{~m}$, which is less than $0.5 \%$

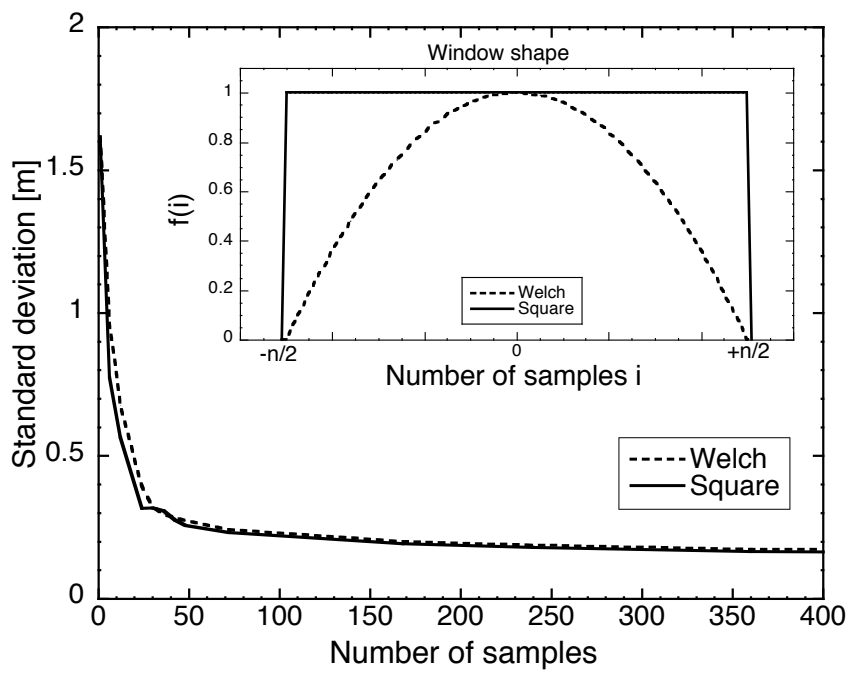

Fig. 4. Standard deviation of the NBRef data as a function of number of samples $(n)$ for a square (boxcar) and Welch window. Note that with a sample time of one hour the number of samples is equivalent to hours. In the inset the shapes of the Welch and square weighing functions $\left(f_{i}\right)$ are displayed.

of the observed average annual velocities. This averaging period removes all variability on time scales of days and smaller but ensures that variability on weekly and larger timescales is maintained. Note that this poses a limit to our temporal resolution. Velocities will be presented using $n_{\mathrm{p}}=n_{\mathrm{v}}=240$.

To check the data for any artificial or natural periodicities, we performed a frequency analysis of the non-averaged NBRef data. Results are presented as a Lomb periodogram in Fig. 5. This analysis shows significant (95\% confidence) peaks at $24 \mathrm{~h}, 12 \mathrm{~h}, 8 \mathrm{~h}, 6 \mathrm{~h}$ and shorter periods. In addition a peak at periods close to 15 days can be observed, although barely significant at the 5\% level. The strength of all these peaks is not influenced by the automatic outlier removal procedure. The peaks are also present in the data collected at the stations on the glacier itself.

The observed periodicities are most likely explained by the influence of the atmosphere on the accuracy of the GPS signal. The traveling time of the signal send by GPS satellites is susceptible to atmospheric conditions, most markedly to ionospheric conditions, but also to e.g. the atmospheric tide. As explained in Sect. 2.2, layers of ionized particles in the ionosphere refract the signal and increase the traveling time. This delay varies on several time scales among wich diurnally.

The atmospheric tide is the result of periodic heating of the atmosphere by solar radiation and by gravitational pull of the Moon. In the stratosphere and troposphere periodic heating of water vapor and ozone through absorption of solar radiation also results in refraction of the GPS signal. The effect is stronger higher in the atmosphere where it has a period of $12 \mathrm{~h}$ while in the lower atmosphere the period is $24 \mathrm{~h}$. 


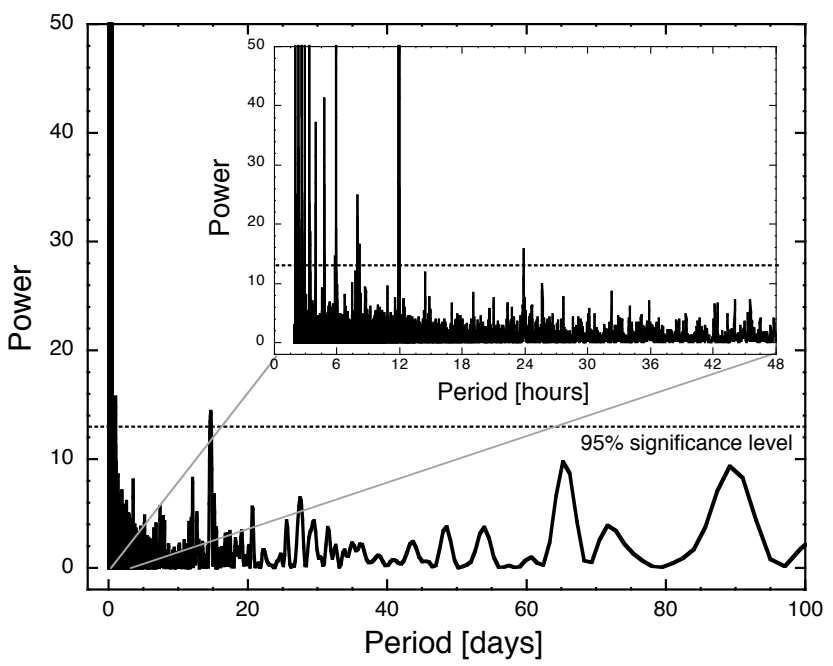

Fig. 5. Lomb periodogram of NBRef data collected between March 2006 and April 2008. The dotted line indicates the $95 \%$ significance level.

Table 5. Annual flow velocities of Nordenskiöldbreen. $V_{\mathrm{av}}$ $\left(\mathrm{m} \mathrm{yr}^{-1}\right)$ is calculated using Eq. (1), with $n_{\mathrm{p}}=n_{\mathrm{v}}=240$. A velocity year runs from day 91 to day 90 of the following year. Period refers to multi-year averages: 2006-2009, NBRef, NB1, NB2, NB4; 2007-2009, NB3, NB5H, NB9; 2006-2007 and 2008-2009, NB6. Italic values represent values based on less than $95 \%$ correct records.

\begin{tabular}{lcrrr}
\hline Station & 2006-2007 & 2007-2008 & 2008-2009 & \multicolumn{1}{c}{ Period } \\
\hline NBRef & $0.4 \pm 0.9$ & $0.2 \pm 0.5$ & $0.1 \pm 0.3$ & $0.1 \pm 0.3$ \\
NB1 & $3.6 \pm 0.9$ & $3.0 \pm 0.5$ & $2.8 \pm 0.3$ & $3.1 \pm 0.3$ \\
NB2 & $0.8 \pm 1.0$ & $1.3 \pm 0.5$ & $1.4 \pm 0.2$ & $1.1 \pm 0.2$ \\
NB3 & - & $53.3 \pm 0.9$ & $54.6 \pm 0.4$ & $53.9 \pm 0.6$ \\
NB4 & $47.2 \pm 1.0$ & $48.7 \pm 0.5$ & $50.9 \pm 0.3$ & $49.0 \pm 0.5$ \\
NB5H & $22.9 \pm 2.5$ & $24.8 \pm 0.8$ & $26.9 \pm 0.4$ & $25.6 \pm 0.4$ \\
NB6 & $42.9 \pm 1.1$ & - & $47.5 \pm 0.4$ & $45.2 \pm 0.4$ \\
NB7 & $45.9 \pm 1.0$ & $47.2 \pm 0.5$ & $52.1 \pm 0.3$ & $46.6 \pm 0.5$ \\
NB8 & $40.3 \pm 0.8$ & $41.9 \pm 0.5$ & $48.2 \pm 0.3$ & $41.1 \pm 0.5$ \\
NB9 & - & $55.8 \pm 1.2$ & $58.2 \pm 0.5$ & $57.0 \pm 0.5$ \\
\hline
\end{tabular}

In addition, its higher harmonics of $8 \mathrm{~h}$ and $6 \mathrm{~h}$ match the observed peaks. The lunar tide introduces a period of 14.76 days, which is close to the found peak at 15 days.

Besides the diurnal variations in ionospheric electron content and the atmospheric tide, other possible explanations of the observed periodicities are the multipath error, which has a repeat time of $23: 56 \mathrm{~h}$, the orbital repeat time of the GPS satellites (11:58 $\mathrm{h}$ and 23:56h) and the resetting of our GPS every $24 \mathrm{~h}$. These effects will likely have some effect on the found periodicity. However, especially the resetting of the GPS is expected to be small in comparison to the periodicity induced by the ionosphere. Note that all these frequencies are eliminated when applying a running average with $n>24 \mathrm{~h}$.

\subsection{Velocity observations}

The main purpose of the GPS observations is to determine the surface velocity of a glacier and its spatial and temporal variations. As an example we present the results obtained at Nordenskiöldbreen. Firstly, we present the annual average velocities and a comparison with DGPS determined velocities. Secondly, we discuss the velocity variations on weekly to monthly time scales.

\subsubsection{Annual velocity variations}

Table 4 presents a comparison between GPS and DGPS determined period average velocities. The GPS average velocities cover the same period as the DGPS velocities, and are calculated in the two different ways described in Sect. 2.2 $\left(V_{\mathrm{av}}, V_{\mathrm{be}}\right)$. In both cases they are based on data in which $n_{\mathrm{p}}=n_{\mathrm{v}}=240$.

Table 4 shows that $V_{\text {av }}$ and $V_{\text {be }}$ are in agreement. The estimated uncertainty in $V_{\text {be }}$ is slightly larger because a small offset in one or both of the values can lead to a larger error. However, the larger $n_{\mathrm{p}}$ and $n_{\mathrm{v}}$ the smaller this effect is. Note that for NB8 only about $80 \%$ of the datapoints are correct compared to more than $99 \%$ for the other stations (Table 4). Comparing the GPS velocities with the DGPS velocities $\left(V_{\text {dgps }}\right)$, the agreement is fairly good. On average the velocities differ by about $4 \%$ from the DGPS velocity; the difference is never larger than $11 \%$. The largest differences are found for NB7 and NB8 which can be explained by instrumental problems caused by rime formation on the sensors. In general the differences for the period 2006-2007 are larger than those for 2007-2008. Since our system is very sensitive to the ionospheric conditions, different ionospherice conditions in both years might explain the difference. However, the $\sigma$ in the NBRef observations does not differ significantly between these two years (Table 2), indicating that the ionospheric conditions were very similar. We therefore do not have an explanation for the observed difference.

In Table 5 the average annual velocities $\left(V_{\mathrm{av}}\right)$ are presented. Since NBRef is a stationary station on rock, its velocity should be $0 . \mathrm{m} \mathrm{yr}^{-1}$. The table shows that, within the uncertainty limit, this is the case. The stations on the glacier show variations of $V_{\mathrm{av}}$ between $40 \mathrm{~m} \mathrm{yr}^{-1}$ on the flatter parts of the main flow line to more than $50 \mathrm{~m} \mathrm{yr}^{-1}$ on the steeper parts of the flow line. The stations placed on the side stream, NB1 and NB2, only move a few meters per year. Station NB5H, is also not located on the main flow line, and moves with intermediate velocities due to increased side drag. Highest velocities are observed closest to the front and higher up on the flow line. The local topography is likely the main controlling factor in the velocity and its variations along the flowline. However, the correlation between driving stress, which is proportional to the ice thickness and the surface slope, and annual velocity is weak (not shown). This can partly be explained by the limited knowledge of bedrock 

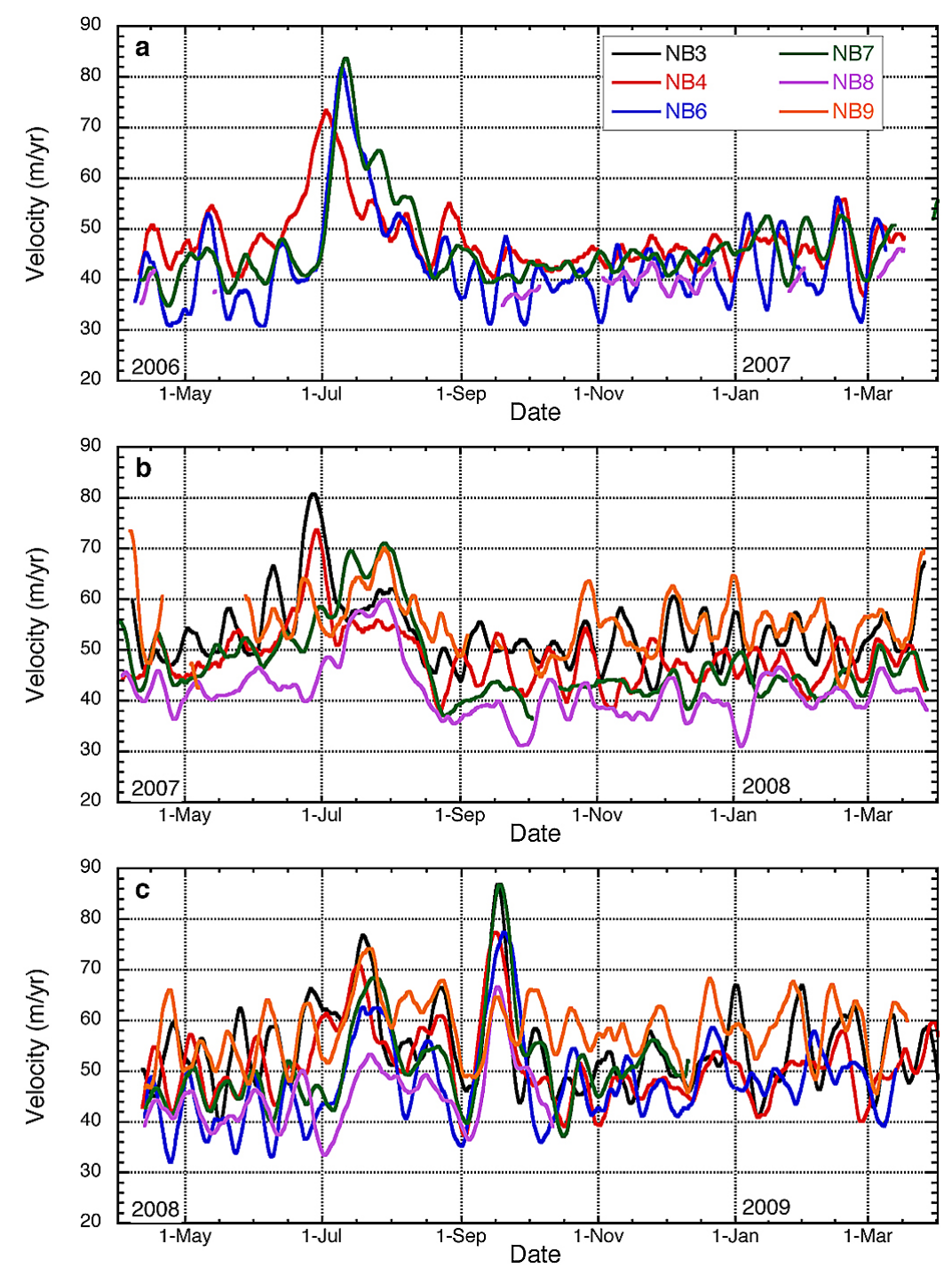

Fig. 6. Time series of velocity measurement of the stations on the central flow-line for the period 2006-2007 (a), $2007-2008$ (b) and 2008-2009 (c). A running average of $240 \mathrm{~h}$ is applied.

topography, ice thickness, and thus driving stress, but might also be caused by not negligible longitudinal stresses.

All stations on the mainstream of Nordenskiöldbreen (NB3-NB9) show an increase in velocity from 2006 to 2009. This increase cannot be related to an increase in melt in these years. The mass balance observations show large interannual variations for this period as does the equilibrium line elevation (not shown). The larger average values for 2008-2009 are (partly) caused by the second summer velocity peak in september 2008 (Fig. 6) which is related to rain fall and discussed in more detail in the next section.

\subsubsection{Short term velocity variations}

A major advantage of the used GPS system is the temporal resolution of the obtained velocities. However, the accuracy of the GPS is in the order of $1.6 \mathrm{~m}$ and probably increases when solar and thus iononospheric activity increases. Averaging over the right period is therefore essential to discern signal from noise. Larger averaging periods decrease the amplitude of the velocity variations and increase the detectable period of the variations. Figure 7 illustrates the difference between averaged and not averaged velocity data for NB4. From the figure it is clear that it is difficult to discern a pattern from the noisy not averaged signal. Furthermore, flow velocities seem to be very large, on the order of 50 to $100 \mathrm{~m} \mathrm{day}^{-1}$. This is because when you determine the absolute velocity $\left(\left(v_{\phi}^{2}+v_{\lambda}^{2}\right)^{0.5}\right)$ you lose all directional information, resulting in an overestimation of velocity which depends on the error in a single observation. 


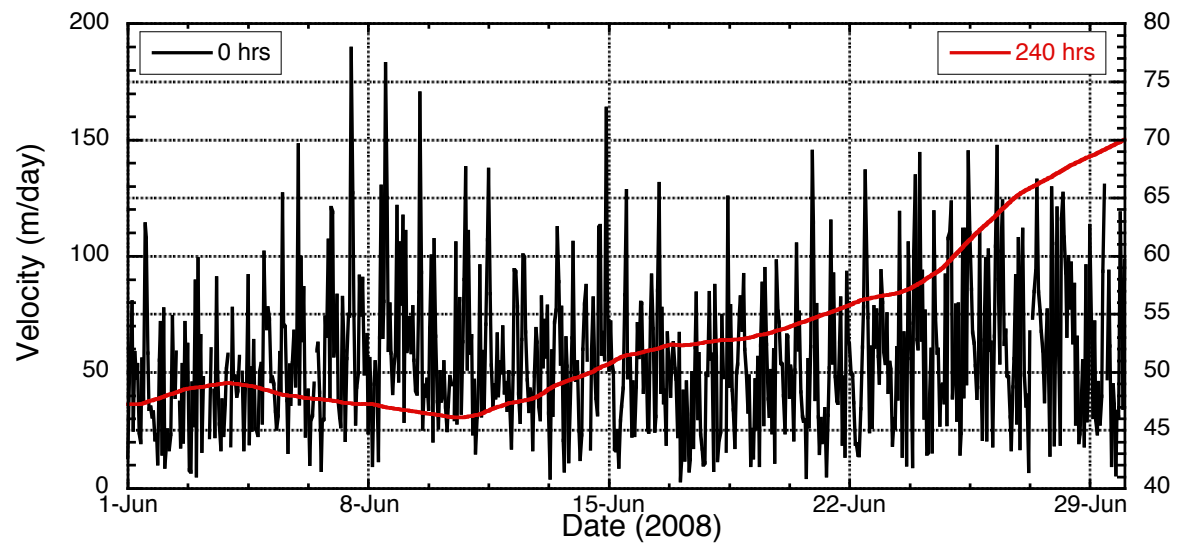

Fig. 7. Time series of velocity measurement of NB4 for June 2008. The black line illustrates the velocity when no averaging is applied, the red line when a running average of $240 \mathrm{~h}$ is applied. Note that the unit of velocity for the not averaged velocity is $\mathrm{m} \mathrm{day}^{-1}$.

Figure 6 shows the velocities of all stations on the central flow line of Nordenskiöldbreen. The figure shows that the velocities vary around the annual averages of 40 to $50 \mathrm{~m} \mathrm{y}^{-1}$ as presented in Table 5, with a marked increase in velocities in summer. Furthermore, throughout the time series, but best visible in winter when meltwater induced speed up does not dominate the signal, the observed velocities show variations on time scales of 15 to 20 days.

The observed increase in velocity in summer is related to the increase in amount of available meltwater. The observed maximum values can reach up to twice the annual average value. In the summer of 2006 all three available stations show a clear peak, with the highest maximum velocity of $85 \mathrm{~m} \mathrm{yr}^{-1}$ occurring at NB7. However, in 2007 only the two lower stations NB3 and NB4 show a well-defined maximum, while the higher stations (NB7-NB9) have a much broader peak. In 2008, it is the other way around, a broad peak for NB3 and NB4 and a more distinct peak for NB6-NB9. An interesting feature in 2008 is the very strong temporary increase in velocity at NB3, NB4 and NB6-NB8 in September. This peak can be related to high September temperatures in combination with more than average amount of precipitation. A similar peak has been observed on glaciers on Vestfonna and Austfonna in the north east of Svalbard and on Kronebreen in the north west of Svalbard (M. Sund, personal communication, 2010).

Correlation analyses shows no significant lag between the timing of the maximum velocity at the different sites on the glacier. The most likely reason is the relatively small distance between the stations (largest distance between two sites is $\pm 13 \mathrm{~km}$ ) in combination with a fast response time of the system and the limited temporal resolution of our observations.

Even after differencing the glacier stations with the NBRef data, all sites still show velocity fluctuations on time scales of 15 to 20 days, which is a larger period than the 15 day peak found in the NBRef data. There are no obvious expla- nations for this behaviour. The closest periodic behaviour in the ionosphere is the lunar tide with a period of 14.76 days. Another explanation could be oceanic tide. Recent radar observations show bed elevations below sea level from the front up to NB7 (R. Petterson, personal communication, 2010). On the other hand, we also observed these type of fluctuations on other glaciers on Svalbard and Greenland. For most of these glaciers oceanic tide is not a likely explanation. Furthermore, there is no significant correlation in timing of the fluctuations between the different glaciers, making the influence of the GPS satellite configuration unlikely.

To investigate to what extend the velocity variations are related to temperature and/or mass balance (gradients) we correlate these quantities. Figure 8 shows the time series of the GPS stations NB4 and NB6 located on the central flow-line over 2008, in combination with observed temperature and changes in the surface height obtained from the sonic altimeter at NB5H, illustrating melt rates. From auto-correlation analysis (using data with $n_{\mathrm{p}}=n_{\mathrm{v}}=24 \mathrm{~h}$ ) a significant positive correlation is found between temperature and velocity in the summer months (days 150-250), with temperature leading velocity by about 3 days. For the same period a significant correlation is found between melt rates and velocity, melt rate leading velocity by about 4 days. Furthermore, the timing of the velocity peak in summer coincides with the first half of the melting period, and peak velocities are reached about 40 days after the onset of melt. Note that the fact that we have to average our data makes it impossible to find correlations on shorter time scales than a few days. The observed velocities fluctuations in winter show no correlation with either temperature or melt rates. 


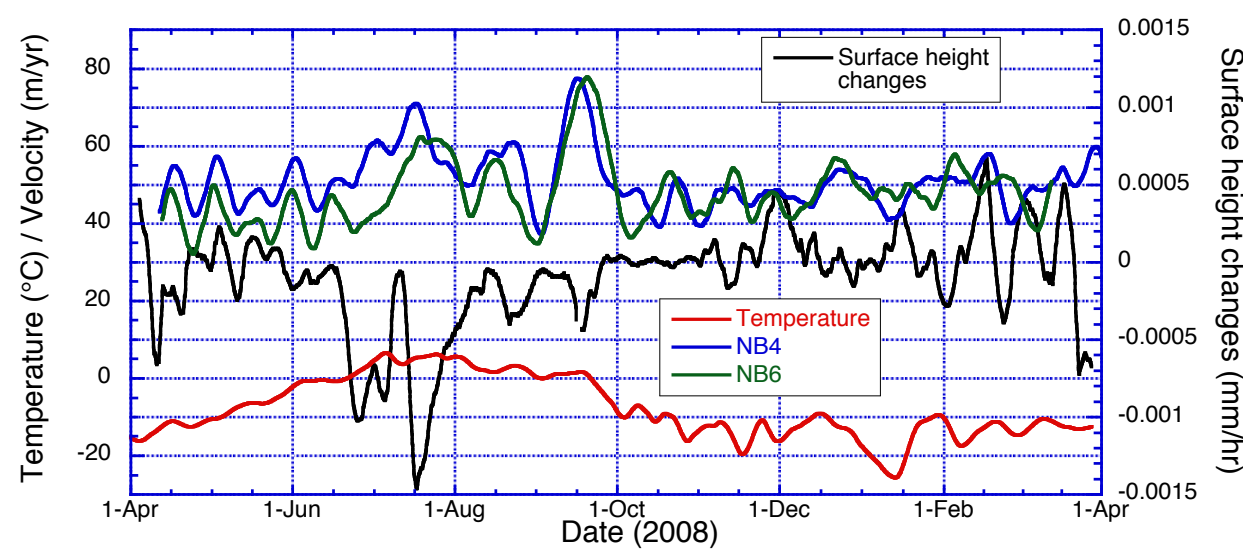

Fig. 8. Time series of temperature, surface height changes and velocity of two stations, NB4 and NB6, for 2008. Surface height changes are derived from sonic height ranger data at NB5H. Negative surface height changes illustrate melt rates. All variables are calculated with a running average of $240 \mathrm{~h}$.

\section{Discussion}

Nordenskiöldbreen is not a very fast-flowing glacier with annual average velocities of about $45 \mathrm{~m} \mathrm{yr}^{-1}$. For example Kronebreen, a tide water glacier in the north west of Svalbard shows velocities up to $600 \mathrm{~m} \mathrm{yr}^{-1}$ close to the front (Kääb et al., 2005). The main difference between these glaciers is that Kronebreen has a floating tongue, whereas Nordenskiöldbreen is grounded for most of its front. Nevertheless, the glacier does exhibit a relation between the melt rate and the flow speed, with a velocity peak of about twice the annual average value in the melting season. However, due to the short summer and the limited temporal resolution the relation between melt water and velocities is rather diffuse making it difficult to correlate the increased velocities to either the start of the melt season or a peak in melt rates.

Comparison of the velocity fluctuations of Nordenskiöldbreen with observations from other glaciers is only possible for the summer period, since detailed winter measurements are scarce. The variation in summer in surface motion of glaciers in the Alps, such as described in Iken and Bindschadler (1986) and Mair et al. (2003) show several episodes with high velocities occurring directly related to meltwater pulses. A similar direct relation has been found on the Greenland ice sheet by Joughin et al. (2008), Van de Wal et al. (2008) and Shepherd et al. (2009), but also on other glaciers on Svalbard (Nuttall et al., 2005; Rippin et al., 2005). Compared to the aformentioned studies the direct relation between melt water pulses and flow velocity is not as strong on Nordenskiöldbreen as on Alpine glaciers or outlet glaciers of the Greenland ice sheet. This is partly due to the reasonably low mean velocity of Nordenskiöldbreen in combination with the necessity to average our data in order to distinguish signal from noise. Note also that the latter two studies are difficult to compare to our observations due to the different time scales (one to several days) of their observations.

\section{Summary and conclusions}

Precise measurements of ice-flow velocities are necessary for a proper understanding of the dynamics of glaciers and their response to climate change. We use stand-alone singlefrequency GPS receivers for this purpose. Our system can operate unattended for 1-3 years, allowing uninterrupted measurements for long periods at a daily or weekly temporal resolution.

The simple design and robustness of our system makes it possible to deploy several receivers on a single glacier and study spatial patterns. The system can therefore provide information on locations where space-borne techniques struggle due to a lack of distinguishable features or coverage. The combination of the low cost and the ability to function for longer time periods is a major advantage of this system for glaciological applications. A limiting factor is its accuracy. In order to distinguish signal from noise it is necessary to average the obtained time series, decreasing the temporal resolution. As a result, the system works less well on slow moving glaciers. However, depending on the average velocity of the measured ice flow, velocity-events on time scales of days to weeks are distinguishable throughout the year.

As an example of the functioning of our system we presented data from 9 receivers deployed on Nordenskiöldbreen, Svalbard. The presented data cover the period March 2006 until May 2009.

Data from a stationary reference site show a standard deviation of $1.62 \mathrm{~m}$ in its average location. DGPS measurements of the reference site are within the calculated standard deviation. In addition, DGPS determined velocities agree reasonably well with our observations. However, because the ionospherice conditions have a large influence on the signal delay and thus the found standard deviation, changes in ionospheric conditions will have a significant influence. The observational period of 2006-2009 is at a Solar ionospheric 
minimum, and the standard deviations are therefore likely to be a minimum value. Spectral analyses of the reference site data show periodicities in the data that can largely be attributed to the atmospheric influence on the GPS signal, especially to the diurnal variations in the ionosphere.

Nordenskiöldbreen is not a very fast flowing glacier showing annual average velocities between 40 and $55 \mathrm{~m} \mathrm{yr}^{-1}$ on the central flow-line. On weekly to monthly time-scales we observe a peak in the ice-flow velocities at the beginning of July during the period with the highest melt-rates. However, due to the limited temporal resolution the relation between melt water and velocities is rather diffuse making it difficult to correlate the increased velocities to either the start of the melt season or the peak in melt rates. The highest measured velocities vary between 60 and $90 \mathrm{~m} \mathrm{yr}^{-1}$. No significant lag can be observed between the timing of the maximum velocity in the lower and higher stations. Likely, this is a result of the short distance between the sites (largest distance between two sites is $\pm 13 \mathrm{~km}$ ) and the necessity to average the data limiting our temporal resolution. In summer the ice velocity is significantly correlated with air temperature and melt rates.

Velocity fluctuations with a period of 15 to 20 days are observed in winter. They are not related to temperature or mass-balance changes. Possible explanations for the variability in winter are lunar and oceanic tidal effects. The winter fluctuations were also found on other glaciers on Svalbard and Greenland where oceanic tidal influence is less likely. At present we do not have an explanation for the observed winter variations.

Acknowledgements. The authors wish to thank M. King and an anonymous reviewer for their constructive comments. Furthermore we wish to thank all colleagues involved with development of the system and the fieldwork, especially, Björn Sjögren, Jim Hedfors and Rickard Petterson. Elisabeth Isaksson from the Norwegian Polar Institute, Jarl Pedersen and colleagues from the logistical unit of the Norwegian Polar Institute in Longyearbyen, and the Swedish Polar Research secretariat are thanked for their collaboration and logistical support. We also acknowledge Leczek Kolondra, University of Silesia, Poland for assistance in DGPS processing. This is a contribution to the International Polar Year (IPY) lead project "The dynamic response of Arctic glaciers to global warming" (GLACIODYN). Financial support is provided by the Netherlands Organisation for Scientific Research (NWO) and the Swedish Science Council as part of the IPY.

Edited by: I. M. Howat

\section{References}

Bingham, R. G., Hubbard, A. L., Nienow, P. W., and Sharp, M. J.: An investigation into the mechanisms controlling seasonal speedup events at a High Arctic glacier, J. Geophys. Res., 113, F02006, doi:10.1029/2007JF000832, 2008.

Hagen, J. O., Melvold, K., Pinglot, F., and Dowdeswell, J. A.: On the net mass balance of the glaciers and ice caps in Sval- bard, Norwegian Arctic, Arct. Antarct. Alp. Res., 35(2), 264270, 2003.

Hagen, J. O., Eiken, T., Kohler, J., and Melvold, K.: Geometry changes on Svalbard glaciers: mass balance or dynamic response?, Ann. Glaciol., 42, 255-261, 2003.

Hinze, H. and Seeber, G.: Ice motion determination by means of satellite positioning systems, Ann. Glaciol., 11, 36-41, 1988.

Iken, A. and Bindschadler, R.A.: Combined measurements of subglacial water pressure and surface velocity of Findelengletscher, Switzerland: Conclusions about drainage system and sliding mechanism, J. Glaciol., 32(110), 101-119, 1986.

IPCC, Climate Change 2007: The Science of Climate Change, in: Contribution of Working Group I to the Fourth Assessment Report of the Intergovernmental Panel on Climate Change, edited by: Solomon, S., Qin, D., Manning, M., Marquis, M., Averyt, K., Tignor, M. M. B., LeRoy Moller Jr., H., and Chen, Z., Cambridge University Press, Cambridge, UK, 2007.

Joughin, I., Das, S. B., King, M. A., Smith, B. E., Howat, I. M., and Moon, T.: Seasonal speedup along the western flank of the Greenland Ice Sheet, Science, 320, 781-783, 2008.

Kääb, A., Lefauconnier, B., and Melvold, K.: Flow field of Kronebreen, Svalbard, using repeated Landsat 7 and ASTER data, Ann. Glaciol., 42, 7-13, 2005.

King, M.: Rigorous GPS data-processing strategies for glaciological applications, J. Glaciol., 50(171), 601-607, 2004.

King, M., Edwards, S., and Clark, P.: Precise point positioning: Breaking the monopoly of relative GPS processing, Engineering Surveying Showcase, 40-41, 2002.

Mair, D., Willis, I., Fischer, U. H., Hubbard, B., Nienow, P., and Hubbard, A.: Hydrological controls on patterns of surface, internal and basal motion during three "spring events": Haut Glacier s'Arolla, Switzerland, J. Glaciol., 49(167), 555-567, 2003.

Meier, M. F., Dyurgerov, M. B., Rick, U. K., O’Neel, S., Pfeffer, W. T., Anderson, R. S., Anderson, S. P., and Glazovsky, A. F.: Glaciers dominate eustatic sea-level rise in the 21 st century, Science, 317, 1064-1067, 2007.

Nuttall, A. M. and Hodgkins, R.: Temporal variations in flow velocity at Finsterwalderbreen, a Svalbard surge-type glacier, Ann. Glaciol., 42, 71-76, 2005.

Oerlemans, J., Dyurgerov, M., and van de Wal, R. S. W.: Reconstructing the glacier contribution to sea-level rise back to 1850 , The Cryosphere, 1, 59-65, doi:10.5194/tc-1-59-2007, 2007.

Pfeffer, W. T., Harper, J. T., and O'Neel, S.: Kinematic constraints on glacier contributions to 21 st-Century sea-level rise, Science, 321, 1340-1343, 2008.

Press, W. H., Teukolsky, S. A., Vetterling, W. T., and Flannery, B. P.: Numerical recipes in Fortran 77, second edn., The art of Scientific Computing, Cambridge University Press, Cambridge, UK, 2003.

Rignot, E. and Kanagaratnam, P.: Changes in the velocity structure of the greenland ice sheet, Science, 311, 986-990, 2006.

Rippin, D., Willis, I., and Arnold, N.: Seasonal patterns of velovity and strain across the tongue of the polythermal glacier midre Lovenbreen, Svalbard, Ann. Glaciol., 42, 445-453, 2005.

Shepherd, A., Hubbard, A., Nienow, P., King, M., McMillan, M., and Joughin, I.: Greenland ice sheet motion coupled with daily melting in late summer, Geophys. Res. Lett., 36, L01501, doi:10.1029/2008GL035758, 2009. 
Sunil, P. S., Reddy, C. D., Ponraj, M., Dhar, A., and Jayapaul, D.: GPS determination of the velocity and strain-rate fields on Schirmacher Glacier, central Dronning Maud Land, Antarctica, J. Glaciol., 53(183), 558-564, 2007.

United States Air Force: Navstar GPS user equipment introduction, Techn. rep., United States Air Force, 1996.

USA Department of Defence: Global positioning system standard positioning service performance standard, Techn. rep., Department of Defence, United States of America, 2008.

Van de Wal, R. S. W., Boot, W., van den Broeke, M. R., Smeets, C. J. P. P., Reijmer, C. H., Donker, J. J. A., and Oerlemans, J.: Large and rapid melt-induced velocity changes in the ablation zone of the Greenland Ice Sheet, Science, 321, 111-113, 2008.
Vincenty, T.: Direct and inverse solutions of geodesics on the ellipsoid with application of nested equations, Surv. Rev., 22(176), 88-93, 1975.

Zwally, H. J., Abdalati, W., Herring, T., Larson, K., Saba, J., and Steffen, K.: Surface Melt-Induced Acceleration of Greenland Ice-Sheet Flow, Science, 297, 218-222, 2002. 